\title{
The Spectral Shift Control Reactor as an option for much improved uranium utilisation in single-batch SMRs
}

\author{
B.A. Lindley*, G.T. Parks \\ Engineering Department, University of Cambridge, Trumpington Street, Cambridge CB2 1PZ, UK
}

H I G H L I G H T S

- A PWR with mixed $\mathrm{D}_{2} \mathrm{O} / \mathrm{H}_{2} \mathrm{O}$ moderator/coolant is investigated for SMR applications.

- Heavy water concentration varied over the cycle to give 'spectral shift' operation.

- Much wetter lattice than normal is neutronically favourable.

- Taller fuel stack is thus needed to ensure acceptable MDNBR.

- $35-43 \%$ increase in uranium utilisation for single batch reactor is possible.

\section{A R T I C L E I N F O}

\section{Article history:}

Received 30 March 2016

Received in revised form 1 August 2016

Accepted 29 August 2016

Available online 28 September 2016

Jel classification:

J. Core Physic

\begin{abstract}
A B S T R A C T
The Spectral Shift Control Reactor (SSCR) uses a mix of $\mathrm{D}_{2} \mathrm{O}$ and $\mathrm{H}_{2} \mathrm{O}$ to moderate and cool the reactor. Initially, a high proportion of $\mathrm{D}_{2} \mathrm{O}$ is used, such that the reactor is substantially under-moderated, with excess neutrons being primarily captured in ${ }^{238} \mathrm{U}$, breeding ${ }^{239} \mathrm{Pu}$. Towards the end of the cycle (EOC), the coolant is predominantly $\mathrm{H}_{2} \mathrm{O}$, thermalising the neutron spectrum and increasing reactivity. Recently, small modular reactors (SMRs) have gained significant interest as a means of providing a power source that requires little maintenance and refuelling. This motivates long cycles and reduced batch operation. For a single-batch reactor, there is typically a $33 \%$ penalty to uranium utilisation compared to a 3-batch reactor. Lattice calculations demonstrate the potential of the SSCR to greatly improve uranium utilisation in single-batch reactors over a range of enrichments. A relatively 'wet' lattice is employed which further improves uranium utilisation. Cases with $5 \%$ and $15 \%$ fissile loading are considered, for which it is respectively possible to achieve $47 \%$ and $39 \%$ increases in natural uranium utilisation using the SSCR relative to a 'reference' light water reactor. In the latter case, if $25 \%$ thorium is mixed into the fuel, the improvement in uranium utilisation increases to a total of $49 \%$. Hence, in both cases, it is possible to in effect eliminate the penalty of using a single fuel batch. The 'wet' lattice introduces substantial thermal-hydraulic challenges due to the significantly higher fuel pin heat flux.

(c) 2016 The Authors. Published by Elsevier B.V. This is an open access article under the CC BY license (http:// creativecommons.org/licenses/by/4.0/).
\end{abstract}

\section{Introduction}

The Spectral Shift Control Reactor (SSCR) uses a mix of $\mathrm{D}_{2} \mathrm{O}$ and $\mathrm{H}_{2} \mathrm{O}$ to moderate and cool the reactor. Initially, a high proportion of $\mathrm{D}_{2} \mathrm{O}$ is used, such that the reactor is substantially undermoderated, with excess neutrons being primarily captured in ${ }^{238} \mathrm{U}$, breeding ${ }^{239} \mathrm{Pu}$. Towards EOC, the coolant is predominantly $\mathrm{H}_{2} \mathrm{O}$, thermalising the neutron spectrum and increasing reactivity. The extra ${ }^{239} \mathrm{Pu}$ bred during the cycle is then burned, allowing the cycle to be extended.

\footnotetext{
* Corresponding author.

E-mail address: bal29@cam.ac.uk (B.A. Lindley).
}

The SSCR concept was suggested by Babcock and Wilcox in the 1960s (Mars et al., 1961), and its viability was demonstrated by a series of experiments (Storrer and Rigg, 1964). The SSCR can operate with a lattice design similar or identical to existing light water reactors (LWRs).

Ronen and Galperin (1980) demonstrated that the SSCR could theoretically achieve an improvement in discharge burn-up of as much as $50 \%$. They showed that, in theory, varying the hydrogento-heavy-metal $(\mathrm{H} / \mathrm{HM})$ ratio in the core for a pure light water coolant can result in a larger improvement (up to $100 \%$ ), but this requires designing an LWR which can operate with a large range of $\mathrm{H} / \mathrm{HM}$ ratios. This can be accomplished to some degree by varying the coolant flow rate, and therefore the void fraction, in a boiling water reactor (BWR). This is realised in the Advanced Boiling 
Water Reactor (ABWR) (Fennern, 2007). The core flow rate and void fraction are subject to thermal-hydraulic constraints which limit the amount of spectral shift control which is possible. A second method is to use 'spectral shift rods' which are initially filled with steam, but are filled with water towards EOC. These can replace the water rods in conventional BWR assemblies (Kondo et al., 2012). In principle, it may be possible to increase the spectral shift effect in a BWR by employing a tighter lattice, higher void fraction and a larger number of spectral shift rods, hardening the spectrum at beginning-of-life (BOL) and allowing greater potential for softening it over the core life by increasing the potential for varying the H/HM ratio with burn-up. However, if additional spectral shift rods are used, this has the disadvantage of reducing the core power density.

Multi-batch operation is a compelling alternative to spectral shift to improve neutron economy, as excess neutrons are used to drive burned fuel assemblies.

Recently, small modular reactors (SMRs) have gained significant interest as a means of providing a power source that requires little maintenance and refuelling. This motivates long cycles and reduced batch operation. For a single-batch reactor, there is typically a $33 \%$ penalty to uranium utilisation compared to a 3-batch reactor. A single-batch SSCR for naval reactors was suggested in Kinsey (1963).

Thorium is often proposed as a fuel for thermal and epithermal reactor systems due to its superior breeding characteristics in the thermal spectrum (Yun et al., 2010) and notably the high reproduction factor $\eta$ of ${ }^{233} \mathrm{U}$ over a wide range of energies, including resonance energies (IAEA, 2005). Breeding of ${ }^{233} \mathrm{U}$ from ${ }^{232} \mathrm{Th}$, and subsequent burning of ${ }^{233} \mathrm{U}$, was successfully performed at the Shippingport Light Water Breeder Reactor (Hecker, 1979). Fuel rods containing a mixture of ${ }^{232} \mathrm{Th}$ and highly enriched uranium were used in the SSCR experiments (Babcock and Wilcox, 1960), providing motivation to revisit thorium fuel designs in this study. Here, the enrichment of ${ }^{235} \mathrm{U}$ in $\mathrm{U}$ is limited to $20 \%$ for proliferation resistance reasons.

The neutronic properties of Th fuel allow it to maintain relatively flat reactivity with burn-up once sufficient ${ }^{233} \mathrm{U}$ has been bred, in a relatively thermal neutron spectrum. This makes it well suited to high burn-up open-cycle schemes, where it is useful in limiting the reactivity swing over the cycle and increasing the proliferation resistance of the spent fuel. However, a high burn-up has to be achieved before use of Th becomes worthwhile, as a fissile 'seed' fuel is necessary to start and sustain the reactor. In opencycle schemes, this is typically low-enriched uranium (LEU). LEU seed and Th blanket fuels can be loaded separately and refuelled on different batch schemes. Significant reductions in U consumption cannot be realised due to the need for much higher (up to $20 \%$ ) U enrichment to sustain reactivity, and high burn-up is necessary for the cycle to be worthwhile, which results in materials challenges. There are also thermal-hydraulic challenges resulting from spatial separation of $U$ and Th. Homogeneous mixing of $U$ and Th was found to decrease burn-up relative to enriched $U$, but some denaturing of Th with $U$ was necessary to improve proliferation resistance, and in some cases to produce sufficient power in the blanket at beginning-of-cycle to reduce power peaking (Todosow and Kazimi, 2004). IAEA (2012) found that open-cycle use of Th can lead to an increase in $U$ consumption, and the higher LEU enrichment required negates proliferation resistance advantages, such that the only advantage is the reduced $\mathrm{Pu}$ and minor actinide (MA) production.

Replacement of the $\mathrm{H}_{2} \mathrm{O}$ in a conventional LWR with $\mathrm{D}_{2} \mathrm{O}$ has been the motivation for $U$ and Th pressurised water reactor (PWR) breeder reactor concepts (Hiruta and Youinou, 2013; Takaki and Mardiansah, 2012), although the former required a high leakage design to achieve a negative void coefficient. $\mathrm{D}_{2} \mathrm{O}$ has also been considered for BWRs (Hibi et al., 2001), but this has the severe disadvantage of the potential for tritium leakage in the steam generators of the primary circuit.

The major disadvantage to the SSCR is the requirement for a $\mathrm{D}_{2} \mathrm{O}$ inventory and dilution system. $\mathrm{D}_{2} \mathrm{O}$ production can add significantly to reactor costs (Ramana et al., 2005) and these costs can be expected to be increased by dilution systems which reverse some of the separative work performed in $\mathrm{D}_{2} \mathrm{O}$ production (indeed the $\mathrm{D}_{2} \mathrm{O}$ may need full replacement at EOC, depending on how it is managed in the reactor). $\mathrm{D}_{2} \mathrm{O}$ dilution systems can also be expected to be complex and add to the reactor size. For SMRs, this is disadvantageous, particularly as many SMR designs are 'soluble boron free' to eliminate the size and complexity of the soluble boron dilution system (Franceschini and Petrovic, 2008). An additional disadvantage is the greatly increased production of tritium within the reactor, which necessitates inclusion of a tritium removal system. This will also increase reactor capital cost and complexity.

This paper presents a preliminary design and analysis of the performance of a single-batch SSCR with uranium enrichments of $5-20 \%$. The impact of adding thorium to the fuel is also assessed. In Section 2, a pincell neutronic analysis is performed to derive an appropriate lattice design for the SSCR from a neutronic perspective. In Section 3, the thermal-hydraulic performance of this design is analysed, and appropriate core dimensions are derived. In Section 4, the performance of a representative design based on the assembly geometry derived in Sections 2 and 3 is assessed. In Section 5, the neutronic safety parameters of this design are evaluated. Finally, conclusions are drawn and areas for future work identified.

\section{Pincell analysis}

Reactor physics calculations were performed using WIMS 10 (Lindley et al., 2015). The ENDF/BVII.0 nuclear data library was used.

The unusual spectrum of the reactor is likely to result in errors due to the group scheme and the derivation of 172-group crosssections using a 'typical' thermal reactor spectrum. These errors are likely to be larger with $100 \% \mathrm{D}_{2} \mathrm{O}$ coolant. An assessment of these errors is beyond the scope of this preliminary scoping study and will be carried out in future work.

A single pincell was modelled in WIMS. The pin diameter and lattice pitch were varied to achieve different $\mathrm{H} / \mathrm{HM}$ ratios, and a depletion calculation was performed to estimate the discharge burn-up for a 1-batch core. The H/HM ratio was initially varied by reducing the pin diameter while maintaining a constant lattice pitch, in order to maintain a constant reactor power density (the pin power was held constant at $18 \mathrm{~kW} / \mathrm{m}$ ). However, for the case with the highest $\mathrm{H} / \mathrm{HM}$ ratio, the pin pitch was increased in order to examine reactor physics performance at high $\mathrm{H} / \mathrm{HM}$ ratios while maintaining a pin that is practical to fabricate.

4\% leakage was assumed, although the true figure will be strongly influenced by reactor dimensions. The leakage can also be expected to be larger with $\mathrm{D}_{2} \mathrm{O}$ coolant as a result of the increased neutron migration length. This is neglected here but considered further in Section 4.

$5 \%, 10 \%$ and $15 \%$ enriched uranium was considered. While enrichments above 5\% are not currently utilised due to licensing and material limits, they are often investigated for future applications, e.g. very long cycle lengths, which is compatible with the objectives of this paper. Enrichments higher than 5\%, and use of thorium in an open fuel cycle, have been considered in other water-cooled reactor concepts, e.g. Todosow and Kazimi (2004), Inoue (2004). 
With long cycle lengths, it becomes challenging to limit reactivity swing and power peaking over the core life, which could potentially be mitigated by the SSCR concept.

For $10 \%$ and $15 \%$ enrichments, stainless steel cladding was used, although for $10 \%$ enrichment the discharge burn-up may be sufficiently low that Zr-based cladding is acceptable. Oxide fuel is considered in all cases. Standard compositions and properties were used for these materials.

A fully light water coolant (LWR) was considered as a reference case. The SSCR was modelled using 5 depletion histories: at $0 \%$, $25 \%, 50 \%, 75 \%$ and $100 \% \mathrm{D}_{2} \mathrm{O}$ concentration. For each depletion history, branch calculations were performed at each burn-up step for the other $4 \mathrm{D}_{2} \mathrm{O}$ concentrations. For each depletion step, the average $\mathrm{D}_{2} \mathrm{O}$ concentration since BOL was first determined. The reactivity at each of the $5 \mathrm{D}_{2} \mathrm{O}$ concentrations was then determined by piecewise linear interpolation of the depletion histories for the average $\mathrm{D}_{2} \mathrm{O}$ concentration. This allowed the $\mathrm{D}_{2} \mathrm{O}$ concentration at the current time-step to be set to ensure criticality (i.e. $k$ inf $=1.04$ ). For the scoping study in this section, this procedure is sufficiently accurate to obtain meaningful results, and this history approach is typically performed for void fraction history effects in BWRs.

For $15 \%$ uranium enrichment (and for wetter lattices at $10 \%$ enrichment), the reactor is supercritical at $100 \% \mathrm{D}_{2} \mathrm{O}$ concentration, so the reactor was depleted with $100 \% \mathrm{D}_{2} \mathrm{O}$ coolant over the initial part of the cycle. In practice, this initial excess reactivity would be controlled with control rods or burnable poisons.

The achievable discharge burn-ups are shown in Table 1 . For a conventional lattice with $\mathrm{H} / \mathrm{HM}=\sim 2$, the SSCR achieves $\sim 8 \mathrm{GWd} /$ t higher burn-up than the LWR at 5\% and 10\% enrichment, and $\sim 5 \mathrm{GWd} / \mathrm{t}$ higher burn-up at $15 \%$ enrichment. This improvement obviously results in a larger percentage improvement in uranium utilisation with lower enriched fuel. However, by increasing the $\mathrm{H} / \mathrm{HM}$ ratio to 6.52 in the reactor it is possible to increase the SSCR discharge burn-up by $56 \%, 48 \%$ and $41 \%$ for $5 \%, 10 \%$ and $15 \%$ enriched fuel respectively - giving roughly the same fuel utilisation as a 3-batch core. Such a large increase in H/HM ratio may not be achievable without reducing the core power density.

The discharge burn-up of an LWR can also be somewhat increased by increasing the $\mathrm{H} / \mathrm{HM}$ ratio. This decreases the magnitude of the moderator temperature coefficient (MTC) which also decreases the allowable soluble boron concentration in the coolant. In addition, for a given reactor power density (i.e. assuming the same linear heat rating and lattice pitch), the achievable cycle length is reduced (Table 2) - or alternatively a higher enrichment is required to maintain the same cycle length.

In the SSCR, soluble boron is not necessary to control the core as $\mathrm{D}_{2} \mathrm{O}$ dilution is used instead. It is therefore anticipated that the wetter lattices will not violate MTC constraints (and this is confirmed in Section 5). The substantially higher discharge burn-up of the SSCR also allows the cycle length to be relatively competitive for a wetter lattice.

A homogeneous U-Th fuel was considered. The uranium enrichment was limited to $20 \%$ to satisfy proliferation resistance con- straints. Within this constraint, 3 different U-Th mixtures were considered to give the same overall fissile content as the uranium SSCR cases. The achievable discharge burn-ups are shown in Table 3.

In an LWR, U-Th fuel performs worse than $U$ fuel at $5 \%$ and $10 \%$ fissile content. At 15\% fissile content, the U-Th fuel has virtually identical performance to $U$ fuel, resulting in little motivation to use it. This is not unexpected, as Th fuel neutronic performance generally improves at higher burn-ups, and for $15 \%$ fissile content, the material difference between the $U$ and $U-T h$ fuel is in any case fairly small.

For the SSCR, use of U-Th fuel is not beneficial at 5\% and $10 \%$ fissile content, although the relative benefits of using an SSCR compared to an LWR are higher when U-Th fuel is considered. However, at $15 \%$ fissile content, use of U-Th fuel increases the discharge burn-up by $\sim 5 \mathrm{GWd} / \mathrm{t}$ relative to $\mathrm{U}$ fuel. Given the cost and complexity of considering a $\mathrm{D}_{2} \mathrm{O} / \mathrm{H}_{2} \mathrm{O}$ coolant in the first place, any additional benefits through using Th appear worth pursuing. The relatively good performance of Th in an SSCR can be explained by the relatively high conversion ratio of Th fuels in an epithermal neutron spectrum.

\section{Thermal-hydraulic analysis}

From Section 2, it is desirable to use a wetter lattice than for a normal PWR in order to increase the moderation and improve fuel utilisation. Here this is accomplished by reducing the pin diameter to $7 \mathrm{~mm}$ while keeping the lattice pitch constant. Increasing the lattice pitch would require either increasing the linear heat rate or reducing the power density, which is undesirable. Use of smaller pins allows the heat flux to be minimised for a given $\mathrm{H} / \mathrm{HM}$ ratio and core volumetric power density.

Using $7 \mathrm{~mm}$ fuel pins in a $12.6 \mathrm{~mm}$ lattice results in substantial changes to the reactor thermal-hydraulic design. It is typical for SMRs to maintain roughly the same core temperature change as large LWRs (Ingremeau and Cordiez, 2015). As the fuel stack is shorter in SMRs, this requires a reduction of the coolant mass flux, which in turn reduces the minimum departure from nucleate boiling ratio (MDNBR). This is mitigated by reducing the linear heat rating of the SMR fuel pins relative to large LWRs.

The design of a reduced-moderation PWR (RMPWR) that can satisfy safety requirements was performed by imposing a minimum allowed DNBR when the reactor is assumed to operate at $112 \%$ of its nominal power, $95 \%$ of nominal flow and with a coolant inlet temperature $\left(T_{\text {in }}\right) 2 \mathrm{~K}$ higher than the nominal. This minimum value is selected to be equal to the MDNBR of the reference SMR when analysed in the same conditions, and with the same critical heat flux (CHF) correlation. This approach is not rigorous, but is often used in simplified analyses since it affords reasonable protection against DNB without the need to analyse both nominal conditions and transient-specific power levels. The rationale behind the method is that, when considering DNB, operational (Condition I) transients and transients arising from faults of moderate frequency

Table 1

Discharge burn-up (GWd/t) with different H/HM ratios.

\begin{tabular}{|c|c|c|c|c|c|c|c|c|}
\hline \multirow{2}{*}{\multicolumn{3}{|c|}{$\begin{array}{l}\text { Uranium enrichment } \\
\text { Cladding }\end{array}$}} & \multirow{2}{*}{\multicolumn{2}{|c|}{ M5 }} & \multirow{2}{*}{\multicolumn{2}{|c|}{$\frac{10 \%}{\text { Stainless steel }}$}} & \multicolumn{2}{|l|}{$15 \%$} \\
\hline & & & & & & & \multirow[b]{2}{*}{ LWR } & \multirow[b]{2}{*}{ SSCR } \\
\hline $\mathrm{H} / \mathrm{HM}$ & Pin pitch (mm) & Pin diameter $(\mathrm{mm})$ & LWR & SSCR & LWR & SSCR & & \\
\hline 1.67 & 12.6 & 9.5 & 34 & 40 & 57 & 63 & 89 & 91 \\
\hline 2.51 & 12.6 & 8.5 & 39 & 51 & 65 & 76 & 100 & 109 \\
\hline 3.81 & 12.6 & 7.5 & 39 & 56 & 67 & 84 & 104 & 123 \\
\hline 6.52 & 15.5 & 7.5 & 35 & 56 & 66 & 89 & 108 & 132 \\
\hline
\end{tabular}


Table 2

Relative cycle length (normalised to LWR for $\mathrm{H} / \mathrm{HM}=1.67$ at each enrichment).

\begin{tabular}{|c|c|c|c|c|c|c|c|c|}
\hline \multirow{2}{*}{\multicolumn{3}{|c|}{$\begin{array}{l}\text { Uranium enrichment } \\
\text { Cladding }\end{array}$}} & \multirow{2}{*}{\multicolumn{2}{|c|}{$\begin{array}{l}5 \% \\
\text { M5 }\end{array}$}} & \multirow{2}{*}{\multicolumn{2}{|c|}{$\begin{array}{l}10 \% \\
\text { Stainless steel }\end{array}$}} & \multicolumn{2}{|l|}{$15 \%$} \\
\hline & & & & & & & & \\
\hline $\mathrm{H} / \mathrm{HM}$ & Pin pitch (mm) & Pin diameter $(\mathrm{mm})$ & LWR & SSCR & LWR & SSCR & LWR & SSCR \\
\hline 1.67 & 12.6 & 9.5 & 1.00 & 1.18 & 1.00 & 1.11 & 1.00 & 1.02 \\
\hline 2.51 & 12.6 & 8.5 & 0.92 & 1.20 & 0.91 & 1.07 & 0.90 & 0.98 \\
\hline 3.81 & 12.6 & 7.5 & 0.71 & 1.03 & 0.73 & 0.92 & 0.73 & 0.86 \\
\hline 6.52 & 15.5 & 7.5 & 0.42 & 0.68 & 0.48 & 0.64 & 0.50 & 0.61 \\
\hline
\end{tabular}

Table 3

Discharge burn-up (GWd/t) with different H/HM ratios: U-Th fuel.

\begin{tabular}{|c|c|c|c|c|c|c|c|c|}
\hline \multirow{2}{*}{\multicolumn{3}{|c|}{$\begin{array}{l}\text { Ratio of } 20 \% \text { enriched } U \text { to Th in fuel } \\
\text { Cladding }\end{array}$}} & \multirow{2}{*}{\multicolumn{2}{|c|}{$\begin{array}{l}25 \% / 75 \% \\
\text { M5 }\end{array}$}} & \multirow{2}{*}{\multicolumn{2}{|c|}{$\frac{50 \% / 50 \%}{\text { Stainless steel }}$}} & \multicolumn{2}{|c|}{$75 \% / 25 \%$} \\
\hline & & & & & & & \multirow[b]{2}{*}{ LWR } & \multirow[b]{2}{*}{ SSCR } \\
\hline $\mathrm{H} / \mathrm{HM}$ & Pin pitch $(\mathrm{mm})$ & Pin diameter $(\mathrm{mm})$ & LWR & SSCR & LWR & SSCR & & \\
\hline 1.67 & 12.6 & 9.5 & 26 & 31 & 53 & 61 & 88 & 97 \\
\hline 2.51 & 12.6 & 8.5 & 33 & 44 & 62 & 74 & 99 & 114 \\
\hline 3.81 & 12.6 & 7.5 & 34 & 46 & 64 & 81 & 105 & 128 \\
\hline 6.52 & 15.5 & 7.5 & 30 & 46 & 64 & 86 & 106 & 137 \\
\hline
\end{tabular}

(Condition II) are bounded by the operating conditions mentioned above.

The 'wetter' pin considered here introduces several competing effects:

- Increase in coolant mass flow rate for given mass flux due to larger wetted area. This necessitates a reduction in the coolant mass flux to maintain the same inlet and outlet temperatures, which reduces the pressure drop.

- Increase in the pin surface heat flux which naturally decreases the MDNBR.

- Increased hydraulic diameter, which reduces the core pressure drop.

To resolve these effects, it is necessary to perform a thermalhydraulic analysis to calculate the core pressure drop and MDNBR. The subchannel code COBRA-EN (Basile et al., 1987) is used to perform the thermal-hydraulic analysis on a single 'hot' channel. To examine the effects described above, a more complicated model is not necessary at this stage. Selection of an appropriate CHF correlation is constrained by the relatively high hydraulic diameter of the SSCR, which falls outside the range of validity of many popular correlations (Pang, 2013). The MacBeth correlation is selected. This is related to the Bowring correlation (Roday and Jensen, 2009) which is valid up to a hydraulic diameter of $\sim 30 \mathrm{~mm}$ (Basile et al., 1987), c.f. the $22 \mathrm{~mm}$ hydraulic diameter of the SSCR.

The core pressure drop is calculated at core average conditions.

COBRA is used to derive the pressure drop for the core. However, the overall thermal-hydraulic performance is dictated by the primary circuit pressure drop. To account for the rest of the primary circuit, the following assumptions are made (Lindley et al., 2014):

- The form loss coefficient associated with the total pressure drop loss experienced by the coolant at the core inlet (lower core plate and assembly bottom nozzle) and outlet (assembly upper nozzle and core upper plate) is set to 6.5.

- The core pressure drop (including the above form loss) is assumed to be $30 \%$ of the total primary circuit pressure drop for the reference SMR. This assumption is approximately valid for a large LWR, and is applied here for the purpose of deriving initial estimates for the primary circuit pressure drop.
- The pressure drop in the remainder of the primary circuit is proportional to (mass flux) ${ }^{1.8}$.

Here, the following methodology is applied, with results given in Table 4. A single channel is analysed for a 4-loop large LWR. $T_{\text {in }}, T_{\text {out }}$ (the coolant outlet temperature) and the MDNBR are evaluated. A pin diameter of $9.5 \mathrm{~mm}$ and pin pitch of $12.6 \mathrm{~mm}$ are assumed (Case 1).

An example SMR is assumed, with a fuel stack half that of the large LWR. $T_{\text {in }}$ is maintained the same as for the large LWR. The mass flow rate is adjusted to maintain the same $T_{\text {out }}$ as the large LWR. As discussed above, the MDNBR is therefore lower than for the large LWR. The example SMR is derated to give approximately the same MDNBR as the large LWR. The mass flow is simultaneously decreased to maintain constant $T_{\text {out }}$ (Case 2).

The pin diameter is reduced from $9.5 \mathrm{~mm}$ to $7 \mathrm{~mm}$. The MDNBR and pressure drop are evaluated for the same $T_{\text {in }}, T_{\text {out }}$ and mass flow rate (Case 3 ).

The results of this analysis are given in Table 4. It is clear that the SSCR has an unacceptably lower MDNBR and hence adjustment to the design is required. It is now assumed that the radial power peaking factor of the SSCR is $5 \%$ lower than that of the reference SMR as mechanical shim is not used to control reactivity over life. This is a rough initial assumption. Furthermore, the primary circuit pressure drop of the SSCR is significantly lower than that of the reference SMR. It is now assumed that the constraint on the SMR core height is set by a desire to maintain a given primary circuit pressure drop in order to simplify the plant design and promote natural circulation cooling in accident conditions. ${ }^{24}$

The SSCR core height is therefore increased while maintaining the total pin power (i.e. the linear heat rating is reduced) in order to give the same MDNBR as the reference SMR (results also shown in Table 4). From this analysis, it is found that the primary circuit pressure drop becomes slightly higher for the SSCR than for the reference SMR (Case 4).

Finally, the SSCR core height is set to give the same primary circuit pressure drop as the reference SMR. In order to maintain MDNBR, it is now necessary to assume that the core is derated slightly. This also has the effect of reducing the mass flow (to maintain constant $T_{\text {in }}$ and $T_{\text {out }}$ ) which benefits the primary circuit pressure drop. It is found that the core must be derated by $1 \%$ to maintain the same MDNBR as the reference design (Case 5). 
Table 4

Thermal-hydraulic analysis results.

\begin{tabular}{|c|c|c|c|c|c|c|c|c|c|c|c|c|}
\hline Case & $\begin{array}{l}\text { Pin } \\
\text { diameter } \\
(\mathrm{mm})\end{array}$ & $\begin{array}{l}\text { Pin } \\
\text { pitch } \\
(\mathrm{mm})\end{array}$ & $\begin{array}{l}\text { Linear heat } \\
\text { rating } \\
(\mathrm{kW} / \mathrm{m})\end{array}$ & $\begin{array}{l}\text { Core } \\
\text { Height (m) }\end{array}$ & $\begin{array}{l}\text { No. Grid } \\
\text { spacers }\end{array}$ & $\begin{array}{l}\text { Coolant mass } \\
\text { flux }\left(\mathrm{kg} / \mathrm{m}^{2} / \mathrm{s}\right)\end{array}$ & $\begin{array}{l}\text { Primary circuit } \\
\text { pressure drop } \\
(\mathrm{kPa})\end{array}$ & $\begin{array}{l}\text { Inlet } \\
\mathrm{T}(\mathrm{K})\end{array}$ & $\begin{array}{l}\text { Outlet } \\
\mathrm{T}(\mathrm{K})\end{array}$ & $\begin{array}{l}\text { MDNBR } \\
(\mathrm{W}-3)\end{array}$ & $\begin{array}{l}\text { MDNBR } \\
\text { (MacBeth) }\end{array}$ & $\begin{array}{l}\text { Radial } \\
\text { power } \\
\text { peaking factor }\end{array}$ \\
\hline (1) Large LWR & 9.5 & 12.6 & 18.3 & 3.66 & 8 & 3728 & 476.3 & 565.9 & 600.7 & 1.738 & 1.505 & 1.78 \\
\hline (2) Ref. SMR & 9.5 & 12.6 & 14.6 & 1.83 & 4 & 1491 & 108.4 & 565.9 & 600.7 & 1.705 & 1.536 & 1.78 \\
\hline (3) SSCR & 7 & 12.6 & 14.6 & 1.83 & 4 & 1090 & 100.2 & 565.9 & 600.7 & 0.841 & 0.870 & 1.78 \\
\hline (4) SSCR & 7 & 12.6 & 8.9 & 3.00 & 7 & 1090 & 111.0 & 565.9 & 600.7 & 1.519 & 1.541 & 1.69 \\
\hline (5) SSCR & 7 & 12.6 & 9.0 & 2.93 & 6 & 1079 & 108.2 & 565.9 & 600.7 & 1.495 & 1.517 & 1.69 \\
\hline
\end{tabular}

In summary, the thermal-hydraulics of the SSCR are more challenging than the reference SMR due to the high heat flux at the pin surface. This necessitates increasing the height of the fuel stack to $\sim 50 \%$ more than that of the reference SMR and also derating the core by $\sim 1 \%$ or incurring a $\sim 3 \%$ higher primary circuit pressure drop. This is detrimental to reactor performance and economics, but may be a sufficiently small difference to not affect overall plant economics, especially if superior performance can be demonstrated elsewhere.

\section{Assembly design and analysis}

From the results of the scoping study of the previous section, an SMR assembly design is now specified. A $13 \times 13$ assembly design (as in Otto, 2013) is considered, with 16 guide tube positions to maintain roughly the same guide tube fraction as conventional $17 \times 17$ assemblies in large LWRs and also SMR designs, (NuSCALE POWER LLC, 2012) and likely similar to the mPower design which uses a 'conventional $17 \times 17$ ' assembly.(Lee, 2011) A $7 \mathrm{~mm}$ pin diameter is selected for the SSCR, which is thought to be the lowest allowable within vibration limits and allows the $\mathrm{H} / \mathrm{HM}$ ratio to be increased by a factor of 2.4. Assembly specifications are given in Table 5, and all calculations are performed using this design.

As in Section 2, WIMS was used to perform the lattice calculations with the ENDF/BVII.0 nuclear data library.

Two cases were considered:

- A case where enrichment was constrained to the current 5\% limit for both the reference LWR and the SSCR. In this case, a fuel utilising Th was not considered as this constrains the fissile loading and therefore the cycle length and discharge burn-up. Zircaloy cladding was assumed.

- An SSCR case with 15\% enriched uranium, specified to give long cycle length. A 75\% U 25\% Th fuel was also considered, with the uranium enriched to $20 \%$ to give the same fissile content as the $100 \%$ uranium fuel. Stainless steel cladding was assumed, resulting in a penalty to uranium utilisation.

For the more detailed design calculations in this section, the assembly was depleted directly with the $\mathrm{D}_{2} \mathrm{O}$ concentration curve derived to achieve $k$-inf close to 1.04 over the cycle. As before, the core was assumed to be infinite in the radial and axial direc-

Table 5

Assembly specifications.

\begin{tabular}{lll}
\hline & Reference & SSCR \\
\hline No. of fuel pins & 153 & \\
No. of guide tubes & 16 & \\
Lattice pitch (mm) & 12.6 & 6 \\
Fuel pellet diameter $(\mathrm{mm})$ & 8.19 & 0.42 \\
Cladding thickness $(\mathrm{mm})$ & 0.57 & 7.0 \\
Fuel pin diameter $(\mathrm{mm})$ & 9.5 & 4.79 \\
H/HM volumetric ratio & 1.96 & \\
\hline
\end{tabular}

tions. This more accurate approach tends to give a discharge burn-up slightly lower than the history calculation method used in Section 2.

The lattice calculations were performed by applying a geometric buckling term within WIMS (under the assumption that the reactor is homogeneous) in order to estimate the leakage. It was assumed that the core radius was $92 \mathrm{~cm}$ (not unreasonable for an SMR) and the height of the reference LWR core was $183 \mathrm{~cm}$ (as in Section 3). The SSCR height was set to $296 \mathrm{~cm}$, consistent with Section 3. Assuming that the reactor is homogeneous, this results in an estimated leakage of $4 \%$, as in Section 2. This leakage may not be accurate for these exact reactor dimensions, but will be representative, and allows consistent comparison of the SSCR and reference $\mathrm{LWR}$.

The $\mathrm{D}_{2} \mathrm{O}$ dilution in the SSCR was set such that $k$-effective was unity throughout the depletion given the leakage term, as calculated using the specified reactor dimensions. The leakage is initially substantially higher in the SSCR than the reference LWR, due to the harder neutron spectrum leading to an increased neutron migration length. Over the cycle, the leakage gradually reduces to around $4 \%$, as for the reference $L W R$. It is noted that this increase in leakage due to increase in migration length penalises the achievable discharge burn-up of the various concepts by $\sim 4-5 \mathrm{GWd} / \mathrm{t}$, due to the reduced achievable $\mathrm{D}_{2} \mathrm{O}$ dilution early in the cycle and consequentially softer neutron spectrum.

The variation of $k$-inf with burn-up is given for the $5 \%$ enrichment case and the 15\% fissile loading cases in Figs. 1 and 2 respectively. The $\mathrm{D}_{2} \mathrm{O}$ dilution curves for these cases are given in Figs. 3 and 4 respectively.

For the $5 \%$ enriched case, the initial critical $\mathrm{D}_{2} \mathrm{O}$ concentration is $95 \%$, thus allowing nearly the maximum achievable spectral shift to be performed over the cycle. At $100 \% \mathrm{D}_{2} \mathrm{O}$ concentration and hot full power, the reactor is $\sim 10,000 \mathrm{pcm}$ subcritical. This suggests that it may be possible to use $\mathrm{D}_{2} \mathrm{O}$ as a secondary shutdown measure, although the reactor is still $\sim 3000 \mathrm{pcm}$ supercritical at cold zero power without rods inserted. It is noted that the reactivity is quite sensitive to the $\mathrm{D}_{2} \mathrm{O}$ concentration, and therefore it will

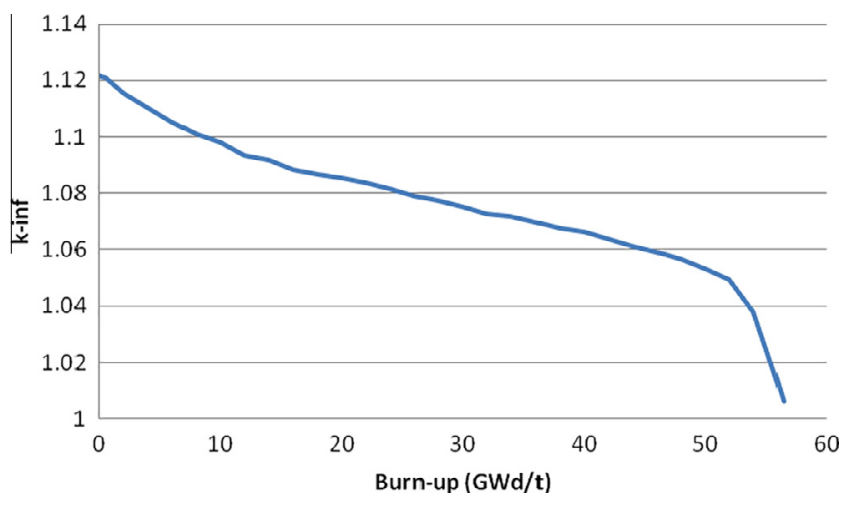

Fig. 1. $k$-Infinity variation with burn-up for the $5 \%$ enrichment case. 


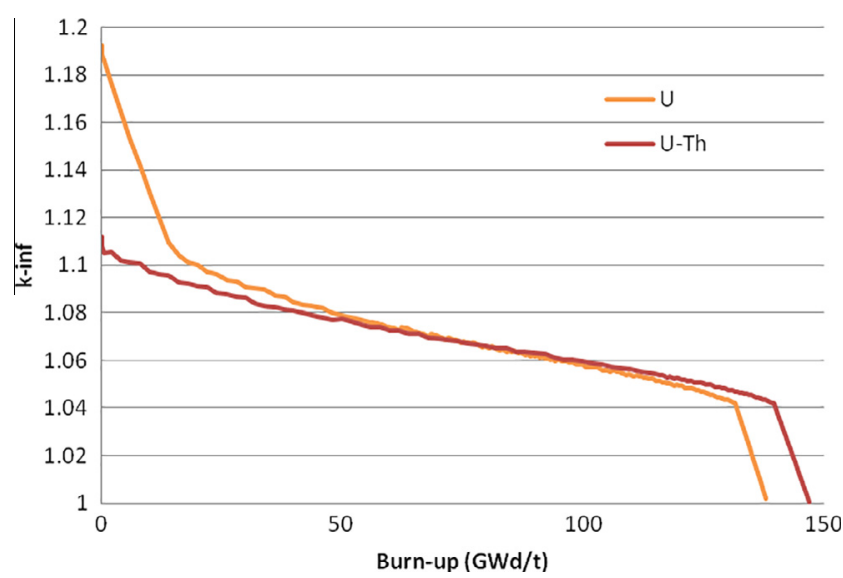

Fig. 2. $k$-Infinity variation with burn-up for the $15 \%$ fissile loading cases.

need to be carefully controlled to maintain a constant reactor power and temperature. However, this may be somewhat analogous to controlling the soluble boron concentration in a conventional PWR.

For the $15 \%$ fissile loading cases, the core is initially supercritical with $100 \% \mathrm{D}_{2} \mathrm{O}$, although only just so with $\mathrm{U}-\mathrm{Th}$. For the U-fuelled core, this may necessitate the use of burnable poisons to control excess reactivity (or a reduction in the core average fissile loading). For the U-Th case, the core is only slightly supercritical at $100 \%$ $\mathrm{D}_{2} \mathrm{O}$ concentration at beginning-of-cycle and therefore slight insertion of control rods can likely be used instead of burnable poisons.

The neutron spectrum of the SSCR over the cycle for the $15 \%$ fissile loading case is shown in Fig. 5. Initially, the resonance flux is relatively high and the thermal neutron flux is suppressed, due to the much lower energy lost in collisions with D atoms compared to $\mathrm{H}$ atoms. Towards end-of-life (EOL), there is a large peak of thermal neutrons due to the relatively wet lattice design.

For each case, a reference LWR assembly was also analysed. It was assumed that an SMR would be designed around a specific core lifetime. The SSCR contains $46 \%$ less fuel per unit area than the LWR assembly. However, taking account of the thermalhydraulic analysis, the SSCR is assumed to have been derated by $1 \%$ and the core is $60 \%$ taller than the reference LWR. The SSCR therefore uses $13 \%$ less fuel than the LWR and therefore requires a higher discharge burn-up to achieve the same cycle length.

For the 5\% enrichment case, the cycle length of the two concepts is enrichment limited and therefore the cycle lengths are different. For the 15\% enrichment case, the enrichment of the fuel in the LWR assembly was selected to match the cycle length of the U-fuelled SSCR. The enrichment required in each case varies, but can be

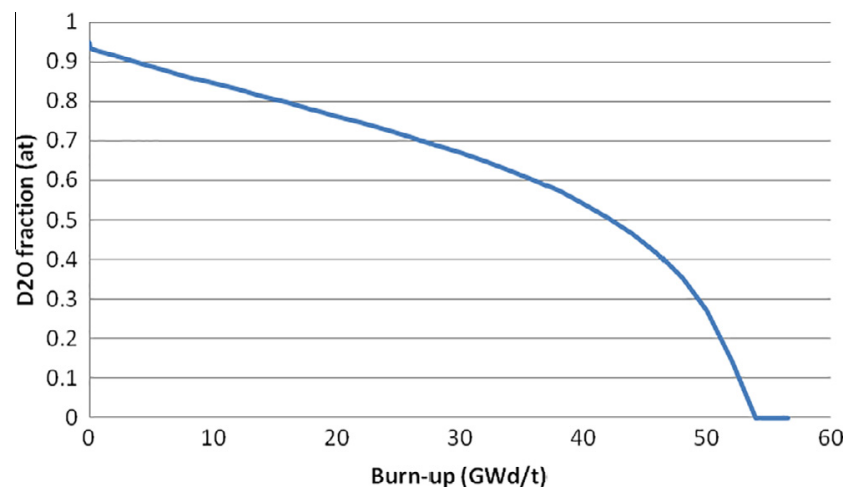

Fig. 3. $\mathrm{D}_{2} \mathrm{O}$ dilution curve for the $5 \%$ enrichment case.

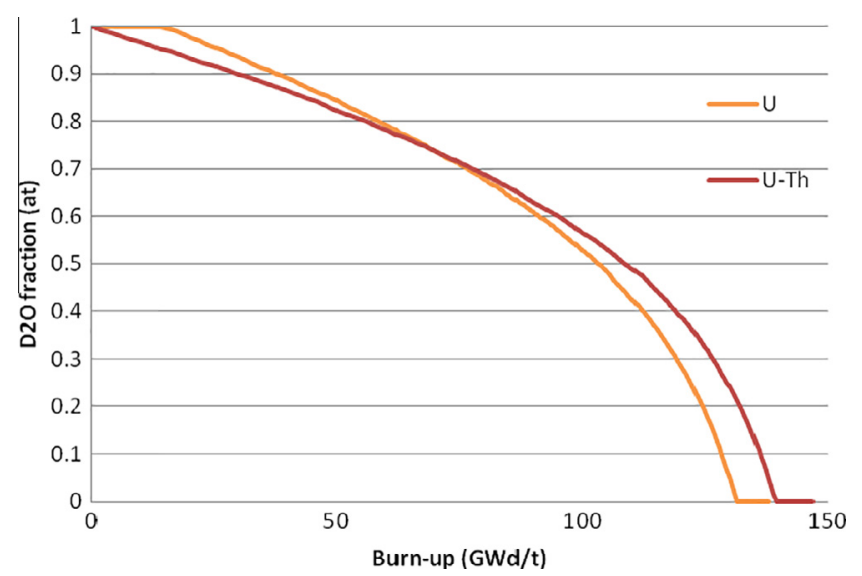

Fig. 4. $\mathrm{D}_{2} \mathrm{O}$ dilution curves for the $15 \%$ fissile loading cases.

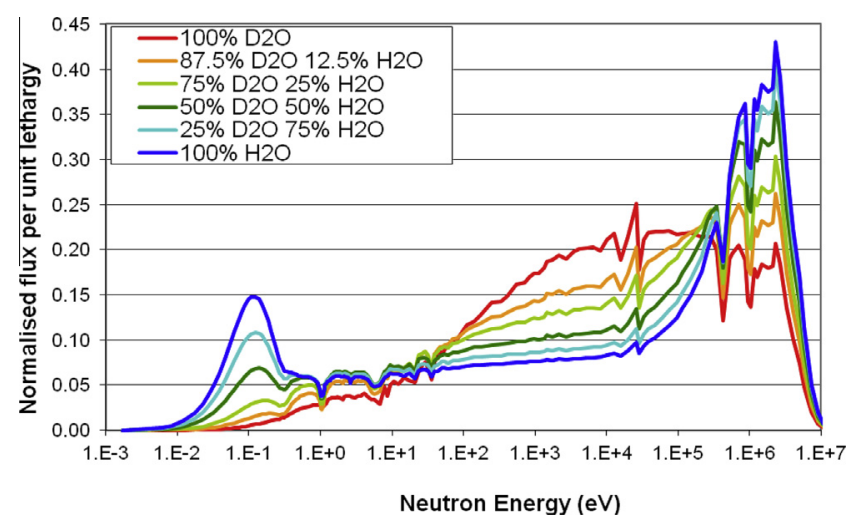

Fig. 5. Neutron spectrum over SSCR assembly lifetime calculated during depletion at different $\mathrm{D}_{2} \mathrm{O}$ concentrations.

accomplished within proliferation limits for the design specified, and as both designs require enrichments substantially above $5 \%$, this is not expected to result in significant additional challenges.

Using a more enriched fuel in the LWR results in a substantially harder neutron spectrum than with $5 \%$ enriched fuel (Fig. 6). As shown in Section 2, an improved neutron economy can be achieved by employing a wetter lattice. This would reduce the power density and require increased enrichment.

Table 6 summarises the relative performance of the assembly designs. A tails enrichment of $0.25 \%$ was assumed when calculating natural uranium and separative work requirements. At 5\% enrichment, relative to the reference design, the U-fuelled SSCR improves natural uranium utilisation by $36 \%$ and the cycle length by $19 \%$. For the $15 \%$ fissile loading design, the U-fuelled SSCR improves natural uranium utilisation by $35 \%$. The U-Th design further improves natural uranium utilisation to a total of $43 \%$ relative to the LWR. The more efficient uranium utilisation of the SSCR also compensates for the lower core fuel mass, allowing the same cycle length to be achieved with a lower enrichment. Therefore, in both cases, the SSCR design can effectively eliminate the penalty of reducing the number of fuel batches from 3 to 1 .

Note that unlike in Section 2, the core volumetric power densities of the LWR and SSCR are not equal. The SSCR core is significantly taller than the reference LWR, leading to a lower core volumetric power density. This mitigates the decrease in core fuel mass, and hence the decrease in cycle length for a given enrichment.

From Section 2, using a wetter LWR lattice can improve U utilisation in the LWR by $\sim 10 \%$, although at the penalty of requiring 


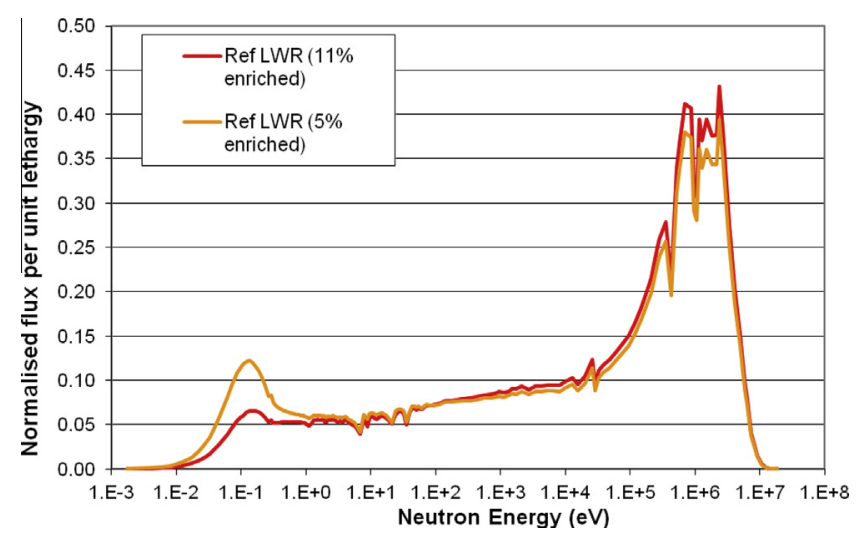

Fig. 6. Effect of increased uranium enrichment on neutron flux spectrum in the reference LWR.

higher enrichment to maintain cycle length. If this design can be achieved within neutronic limits, this would reduce the advantage of the SSCR somewhat.

The composition of the discharged fuel is given in Table 7. The fissile proportion of the Pu discharged from the SSCR is in general lower than that of the reference LWR. This is thought to be due to the more thermal spectrum at end-of-cycle leading to increased burning of ${ }^{239} \mathrm{Pu}$. The quantity of plutonium produced is broadly comparable between concepts, while the quantity of minor actinides ( $\mathrm{Np}, \mathrm{Am}$ and $\mathrm{Cm}$ ) produced for the SSCR is higher than for the LWR. For U-fuelled concepts, the fissile proportion of the discharged uranium is lower for the SSCR than the LWR, as the spectral shift leads to improved fissile utilisation.
Addition of Th to the fuel decreases the quantity of transuranics which are produced, while increasing the fissile proportion of the discharged uranium, due to breeding of ${ }^{233} \mathrm{U}$ and ${ }^{235} \mathrm{U}$. While fuel reprocessing is not considered in this study, it is noted that thorium-containing fuels are in general more difficult to reprocess than uranium-based fuels, and the recovered uranium includes a small amount of ${ }^{232} \mathrm{U}$, which has high energy gamma emitters in its decay chain.

\section{Reactivity coefficients and control}

\subsection{Moderator temperature coefficient (MTC)}

The MTC is calculated over the core life and shown in Figs. 7 and 8 for the $5 \%$ and $15 \%$ fissile loading cases respectively.

For the $5 \%$ case, the MTC is initially very negative and becomes less negative towards EOC as the reactor becomes more optimally moderated, although it is still substantially negative.

For the $15 \%$ case, the MTC is substantially negative throughout. With $100 \% \mathrm{D}_{2} \mathrm{O}$ concentration the MTC initially gets slightly worse. Gradual dilution effects then make it more negative up to a minimum around $\sim 100 \mathrm{GWd} / \mathrm{t}$. While the reactor is substantially under-moderated at BOL, initially thermal fissions are strongly suppressed so that the beneficial effect of reduced thermal fission on MTC is reduced (Harris, 2013). The MTC then becomes less negative as the moderation approaches optimal at EOL. The U-Th fuel has a slightly more negative MTC due to reduced ${ }^{232}$ Th fast fission and the introduction of $\mathrm{H}_{2} \mathrm{O}$ into the coolant at a lower burn-up.

For the $15 \%$ enriched $U$ design, it needs to be established that reactivity control can be implemented at BOL without a positive MTC resulting. Burnable poisons generally make the MTC worse.

Table 6

Assembly performance.

\begin{tabular}{|c|c|c|c|c|c|}
\hline & LWR & & SSCR & & \\
\hline Fuel HM (wt\%) & $\begin{array}{l}5 \%{ }^{235} \mathrm{U} \\
95 \%{ }^{238} \mathrm{U}\end{array}$ & $\begin{array}{l}18 \%{ }^{235} \mathrm{U} \\
82 \%{ }^{238} \mathrm{U}\end{array}$ & $\begin{array}{l}5 \%{ }^{235} U \\
95 \%{ }^{238} U\end{array}$ & $\begin{array}{l}15 \%{ }^{235} U \\
85 \%{ }^{238} U\end{array}$ & $\begin{array}{l}15 \%{ }^{235} \mathrm{U} \\
60 \%{ }^{238} \mathrm{U} \\
25 \%{ }^{232} \mathrm{Th}\end{array}$ \\
\hline Fuel rating $(\mathrm{MW} / \mathrm{t})$ & 31.2 & 31.2 & 35.9 & 35.9 & 36.9 \\
\hline Discharge burn-up (GWd/t) & 39.7 & 117 & 54.0 & 131.5 & 139.5 \\
\hline Cycle length (full power yr) & 3.43 & 10.1 & 4.10 & 10.0 & 10.4 \\
\hline Uranium utilisation (GWd/tNU) & 3.93 & 3.10 & 5.34 & 4.19 & 4.44 \\
\hline Separative work per kg fuel (SWU/kg) & 7.84 & 36.7 & 7.84 & 29.5 & 30.3 \\
\hline Separative work per unit energy produced (SWU/GWd) & 198 & 314 & 145 & 228 & 221 \\
\hline
\end{tabular}

Table 7

Discharged fuel actinide concent.

\begin{tabular}{|c|c|c|c|c|c|}
\hline \multirow[b]{2}{*}{ Fuel HM (wt\%) } & \multicolumn{2}{|l|}{ LWR } & \multicolumn{3}{|l|}{ SSCR } \\
\hline & $\begin{array}{l}5 \%{ }^{235} \mathrm{U} \\
95 \%{ }^{238} \mathrm{U}\end{array}$ & $\begin{array}{l}18 \%{ }^{235} \mathrm{U} \\
82 \%{ }^{238} \mathrm{U}\end{array}$ & $\begin{array}{l}5 \%{ }^{235} U \\
95 \%{ }^{238} U\end{array}$ & $\begin{array}{l}15 \%{ }^{235} \mathrm{U} \\
85 \%{ }^{238} \mathrm{U}\end{array}$ & $\begin{array}{l}15 \%{ }^{235} \mathrm{U} \\
60 \%{ }^{238} \mathrm{U} \\
25 \%{ }^{232} \mathrm{Th}\end{array}$ \\
\hline \multicolumn{6}{|l|}{ Pu discharge vector (\%) } \\
\hline${ }^{238} \mathrm{Pu}$ & 1.6 & 6.1 & 2.8 & 9.2 & 11.4 \\
\hline${ }^{239} \mathrm{Pu}$ & 59.7 & 59.0 & 46.1 & 42.7 & 41.0 \\
\hline${ }^{240} \mathrm{Pu}$ & 21.3 & 17.0 & 27.5 & 24.2 & 22.3 \\
\hline${ }^{241} \mathrm{Pu}$ & 13.4 & 14.3 & 15.2 & 16.3 & 16.8 \\
\hline${ }^{242} \mathrm{Pu}$ & 4.0 & 3.6 & 8.4 & 7.6 & 8.5 \\
\hline \multicolumn{6}{|l|}{ Transuranic production } \\
\hline $\mathrm{Pu}$ kg/Gwthyr & 96.3 & 61.0 & 85.8 & 67.5 & 49.0 \\
\hline Minor Actinide (Np, Am, Cm) kg/Gwthyr & 7.1 & 9.1 & 8.8 & 12.3 & 11.0 \\
\hline \multicolumn{6}{|l|}{$U$ discharge vector } \\
\hline${ }^{233} \mathrm{U}$ & 0.0 & 0.0 & 0.0 & 0.0 & 1.4 \\
\hline${ }^{234} \mathrm{U}$ & 0.0 & 0.1 & 0.0 & 0.1 & 0.4 \\
\hline${ }^{235} \mathrm{U}$ & 1.8 & 6.8 & 1.3 & 3.9 & 5.2 \\
\hline${ }^{236} \mathrm{U}$ & 0.6 & 3.0 & 0.8 & 3.2 & 4.3 \\
\hline${ }^{238} \mathrm{U}$ & 97.6 & 90.2 & 98.0 & 92.9 & 88.8 \\
\hline
\end{tabular}




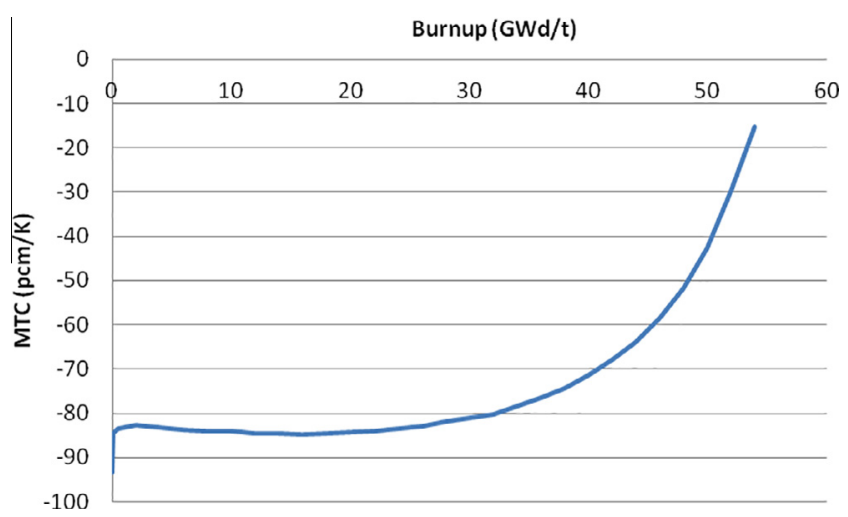

Fig. 7. MTC variation with burn-up for the $5 \%$ fissile loading case.

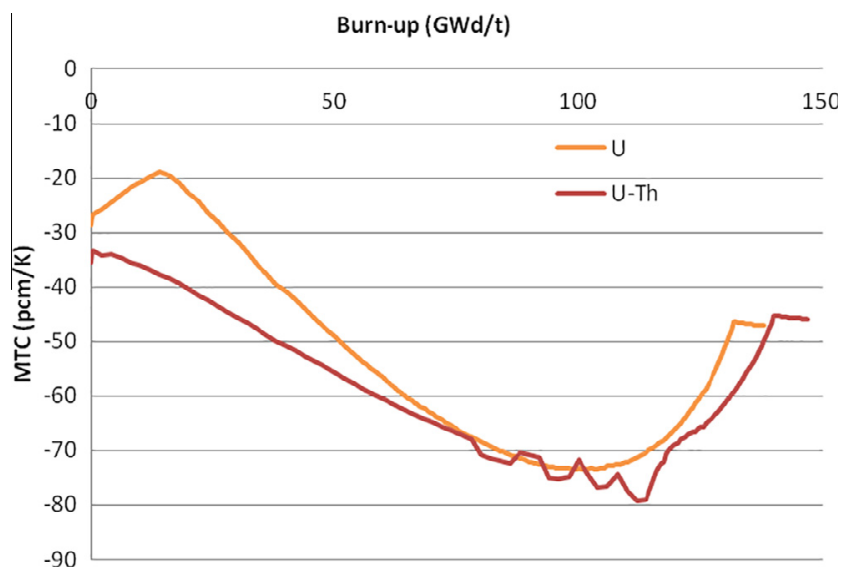

Fig. 8. MTC variation with burn-up for the $15 \%$ fissile loading cases.

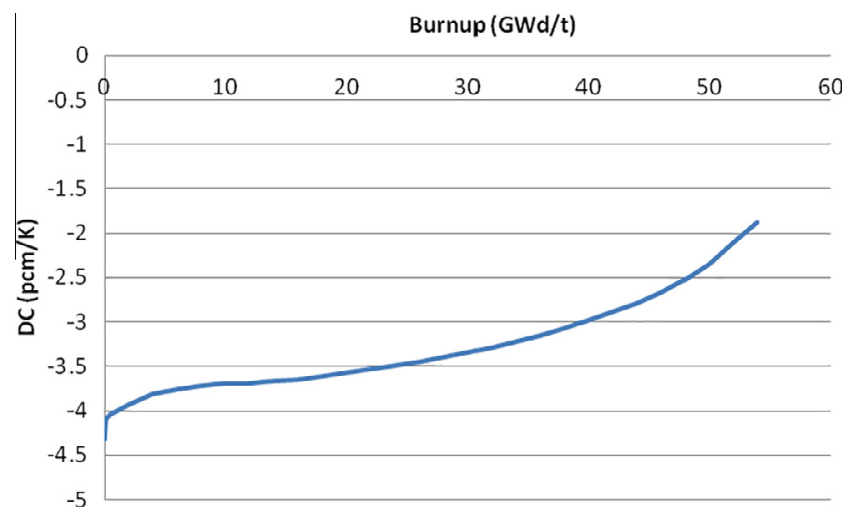

Fig. 9. DC variation with burn-up for the $5 \%$ fissile loading case.

In hard spectrum LWRs, control rods can improve the MTC (Lindley et al., 2014) - this may extend to the SSCR. Lower control requirements may favour U-Th fuel designs or lower enrichment SSCR designs. The relatively negative MTC at BOL may make it more difficult to ensure an adequate cold shutdown margin, which requires further study.

\subsection{Doppler Coefficient (DC)}

The DC is plotted over the cycle for $5 \%$ and $15 \%$ fissile loading in Figs. 9 and 10 respectively. This generally gets less negative over life as fertile material is depleted and the resonance flux in the reactor decreases, reaching a maximum value of $-2 \mathrm{pcm} / \mathrm{K}$ (similar

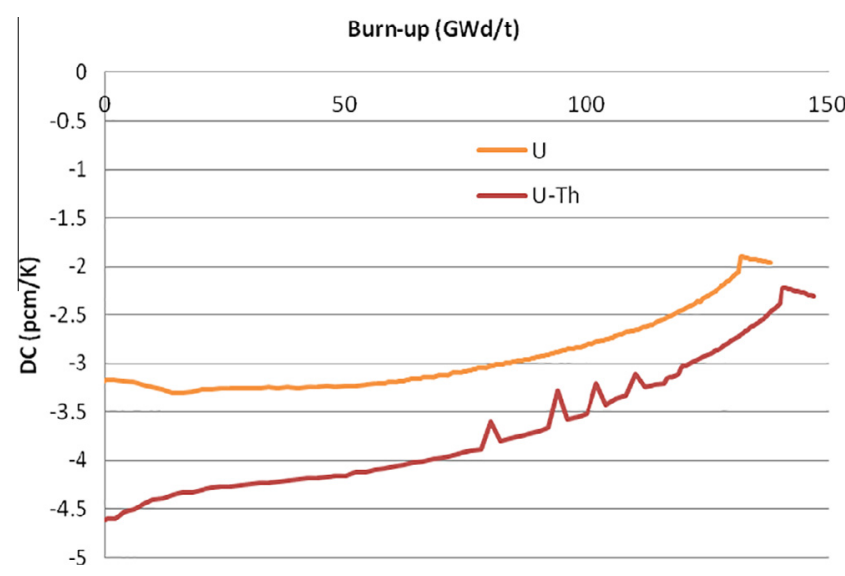

Fig. 10. DC variation with burn-up for the $15 \%$ fissile loading cases.

to conventional LWRs).(AREVA/EDF, 2011) The DC is generally slightly lower with U-Th fuel and is broadly comparable between the $5 \%$ and $15 \%$ enriched cases. As with the MTC, relatively negative DC at BOL may make it more difficult to ensure an adequate cold shutdown margin, which requires further study.

\subsection{High excess reactivity with $100 \% \mathrm{H}_{2} \mathrm{O}$}

The SSCR has a much lower BOL reactivity than the LWR. In the event of an unanticipated $\mathrm{D}_{2} \mathrm{O}$ dilution such that the core is filled with $\mathrm{H}_{2} \mathrm{O}$, the reactivity at $\mathrm{BOL}$ is very large $(0.33,0.38$ and 0.36 for the $5 \%$ fissile loading, $15 \%$ fissile loading $U$ and $15 \%$ fissile loading U-Th cases respectively). The reactivity control problem is greatly exacerbated by the lower or zero use of burnable poisons, which increases the demands on the shutdown rods or necessitates the use of an emergency soluble poison injection system. The feasibility of controlling the reactor therefore requires further analysis - especially as two redundant means of shutting down the reactor are likely to be required (UK office of Nuclear regulation, 2008).

Increased reactivity of fresh fuel when moderated with pure $\mathrm{H}_{2} \mathrm{O}$ could complicate the criticality safety case. For higher enrichment cases (i.e. above 5\%), the criticality safety case for movement of fuel will in any case be challenging, although it is possible the relatively high reactivity of the SSCR assemblies could further complicate this.

\section{Conclusions}

For a reactor constrained to operate using a single batch, the SSCR can substantially improve natural uranium utilisation over a conventional LWR over a range of uranium enrichments. For high burn-up designs, it can be neutronically advantageous to mix some thorium into the fuel. There is a significant neutronic advantage to utilising a substantially wetter lattice than usual. This results in thermal-hydraulic challenges due to the high fuel pin to coolant heat flux. In order to maintain inlet and outlet temperatures, this necessitates using a very slightly lower core power per unit area for the SSCR, and a significantly higher fuel stack, although the latter is achievable for the same primary circuit pressure drop as the reference LWR, due to the larger hydraulic diameter of the SSCR.

With 5\% enrichment, a uranium-fuelled SSCR can achieve $47 \%$ better natural uranium utilisation and 30\% longer cycle length than a reference LWR. The increase in fuel utilisation is comparable to multi-batch designs, hence allowing good performance to be achieved with a single batch while likely remaining within material limits. 
For the considered high burn-up assembly design, a $15 \%$ enriched uranium-fuelled SSCR can achieve 39\% better natural uranium utilisation than a conventional LWR lattice, although there may be some advantage to using a slightly wetter lattice in the LWR. Use of U-Th fuel can further improve natural uranium utilisation to $49 \%$ better than the LWR, while maintaining the enrichment of ${ }^{235} \mathrm{U}$ in $\mathrm{U}$ at $20 \%$. The use of U-Th fuel also reduces the cycle reactivity swing. Assuming that the SSCR core power density is reduced as outlined above, the core fuel mass of the LWR and SSCR are comparable.

In all cases, the MTC and DC are substantially negative throughout the core life. The SSCR has a much lower reactivity swing than a conventional LWR. However, if the core was unintentionally flooded with $100 \% \mathrm{H}_{2} \mathrm{O}$ at BOL, then reactivity control could be difficult, especially given the relatively low burnable poison content in the core and relatively high enrichment. A major drawback of the SSCR is the significant expense and complexity of the $\mathrm{D}_{2} \mathrm{O}$ dilution system and tritium removal systems. The expense of these systems may indeed be prohibitive and hence will be considered in any future work. Any future work should also include a full core analysis to determine core parameters including power peaking, cycle length and control rod worth, and further consider how to address the positive reactivity with $100 \% \mathrm{H}_{2} \mathrm{O}$ at BOL.

\section{References}

AREVA/EDF, 2011. UK EPR PCSR - Sub-chapter 4.3 - Nuclear design. UKEPR-0002043 Issue 04.

Babcock and Wilcox Company, 1960. Spectral shift control reactor basic physics program: quarterly technical reports. In: Office of Technical Services.

Basile, D., Chierici, R., Beghi, M., Salina, S., Brega, E., 1987. COBRA-EN: An upgraded version of the COBRA-3C/MIT code for thermal-hydraulic transient analysis of light water reactor fuel assemblies and cores. In: Report No. 1010/1. ENEL SpA, Milan, Italy.

Fennern, L.E., 2007. ABWR Seminar - Reactor core neutronics. In: GE Energy/ Nuclear Apr 13, 2007.

Franceschini, F., Petrovic, B., 2008. Advanced operational strategy for the IRIS reactor: Load follow through mechanical shim (MSHIM). Nucl. Eng. Des. 12 , 3240-3252.

Harris, A.D.H., 2013. Heavy water as a thorium breeder reactor coolant. University of Cambridge, UK. MEng thesis.

Hecker, H.C., 1979. Summary of the nuclear design and performance of the Light Water Breeder Reactor (LWBR). In: DOE Research and Development Report, WAPD-TM-1326.

Hibi, K., Shimada, S., Okubo, T., Iwamura, T., Wada, S., 2001. Conceptual designing of reduced-moderation water reactor with heavy water coolant. Nucl. Eng. Des. 210, 9-19.

Hiruta, H., Youinou, G., 2013. In: Preliminary neutronic study of D2O-cooled high conversion PWRs. Proc. Global 2013, Salt Lake City, USA.

IAEA, 2005. Thorium Fuel Cycle - Potential Benefits and Challenges. IAEA-TECDOC1450. In: IAEA-TECDOC-1450. International Atomic Energy Agency, Vienna, Austria.
IAEA, 2012. Role of thorium to supplement fuel cycles of future nuclear energy systems. In: Technical Reports Series No. NF-T-2.4. International Atomic Energy Agency, Vienna, Austria.

Ingremeau, J.-J., Cordiez, M., 2015. Flexblue core design: optimisation of fuel poisoning for a soluble boron free core with full or half core refuelling. In: Proc. Int. Conf. ICAPP2015. May 3-6.

Inoue, Y., 2004. Combining thorium with burnable poison for reactivity control of a very long cycle BWR. MIT. MS Thesis.

Kinsey, R.P., 1963. British plans for nuclear ships. In: New Scientist (No. 327). 21 Feb 1963.

Kondo, T., Kitou, K., Chaki, M., Ogha, Y., Makigami, T., 2012. Thermal hydraulic test of advanced fuel bundle with spectral shift rod (SSR) for BWR: steady state and transient test results and analysis. In: Proc. Int. Conf. ICONE 2012 and ASME 2012 Power Conference.

Lee, D., 2011. Generation mPower: B\&W mPower Program. IAEA SMR Technology Workshop, Vienna, Austria, p. 2011.

Lindley, B.A., Zainuddin, N.Z., Ferroni, P., Hall, A., Franceschini, F., Parks, G.T., 2014. On the use of reduced-moderation LWRs for transuranic isotope burning in thorium fuel - Part II: Core analysis. Nucl. Technol. 185, 147-173.

Lindley, B.A., Zainuddin, N.Z., Ferroni, P., Hall, A., Franceschini, F., Parks, G.T., 2014. On the use of reduced-moderation LWRs for transuranic isotope burning in thorium fuel - Part I: Assembly analysis. Nucl. Technol. 185, 127-146.

Lindley, B.A., Newton, T.D., Hosking, J.G., Smith, P.N., Powney, D. J, Tollit, B., Smith, P. J., 2015. In: Release of WIMS10: a versatile reactor physics code for thermal and fast systems. Proc. Int. Conf. ICAPP2015, May 3-6.

Mars, D. et al., 1961. Spectral Shift Control Reactor Design and Economic Study BAW-1241. Babcock and Wilcox Company.

NuSCALE Power LLC, 2012. NuScale plant design overview. NP-ER-0000-1198. NuScale Power, LLC, Corvallis, Oregon, USA.

Otto, R.T., 2013. Core optimization in a thorium-based civil marine propulsion reactor. University of Cambridge. MPhil thesis.

Pang, B., 2013. In: Numerical study of void drift in rod bundle with subchannel and CFD codes. KIT Scientific Reports 7669.

Ramana, M.V., D'sa, A., Reddy, A.K.N., 2005. Economics of nuclear power from heavy water reactors. Econ. Political Weekly 40 (17), 1763-1773.

Roday, A.P., Jensen, M.K., 2009. Study of the critical heat flux condition with water and R-123 during flow boiling in microtubes. Part II - Comparison of data with correlations and establishment of a new subcooled CHF correlation. Int. J. Heat Mass Transf. 52, 3250-3256.

Ronen, Y., Galperin, A., 1980. A comparison between spectral shift control methods for light water reactors. Ann. Nucl. Energy 7, 59-64.

Storrer, J., Rigg, S., 1964. The Vulcain core power experiment,. In: Proc. 3rd U.N. Conf. Peaceful Uses Atomic Energy 1.

Takaki, N., Mardiansah, D., 2012. Core design and deployment strategy of heavy water cooled sustainable thorium reactor. Sustainability 4, 1933-1945.

Todosow, M., Kazimi, M., 2004. Optimization of heterogeneous utilization of thorium in pwrs to enhance proliferation resistance and reduce waste. In: BNL73152-2004 MIT-NFC-065. Brookhaven National Laboratory, Upton, New York, USA.

UK Office of Nuclear Regulation, 2008. Safety Assessment Principles - 2006 edition (Revision 1, February 2008) Paragraphs 449, 451 and 474. In: Engineering Principle for Criticality Safety 2 (ECR.2). <http://www.hse.gov.uk/nuclear/saps/ saps2006.pdf> (accessed 15.10.13).

Yun, D. Kim, T.K. Taiwo, T.A., 2010. Th $/ 233 \mathrm{U}$ multi-recycle in pressurised water reactors: feasibility study of multiple homogeneous/heterogeneous assembly designs. In: Proc. 11th International Exchange Meeting on Partition and Transmutation (IEMPT 11), San Francisco, California, USA, Nov 1-4, 2010. 